\title{
Tecnologia e Educação: Estado da Arte no paisagismo do SENID
}

\section{RESUMO}

\section{Everton Bedin}

bedin.everton@gmail.com

orcid.org/0000-0002-5636-0908

Universidade Luterana do Brasil, Canoas, Rio Grande do Sul, Brasil.

\section{Aline Locatelli}

alinelocatelli@upf.br

Universidade de Passo Fundo, Passo

Fundo, Rio Grande do Sul, Brasil.

\section{Roberto Junior Bedin}

\section{rib-0@hotmail.com}

2-0512-8420

Universidade de Passo Fundo, Passo

Fundo, Rio Grande do Sul, Brasil.
Este artigo traz à tona resultados de uma pesquisa crítico-reflexiva de cunho virtualbibliográfica, realizada no viés dos três anos do evento Seminário Nacional de Inclusão Digital (SENID) sobre as publicações referentes à utilização das tecnologias e a qualificação nos processos ensino e aprendizagem, como suporte exacerbado à formação docente, políticas públicas e currículo flexibilizado. $A$ análise dos dados realizou-se frente à pesquisa Estado da Arte de cunho quali-quantitativo via uso dos artigos completos e resumos expandidos disponíveis na página do evento. Verificou-se, por meio das publicações no desenho do Estado da Arte, a emersão de quatro categorias no viés da temática que findam, nos últimos três anos do SENID, as publicações referentes ao uso das tecnologias na educação. Não obstante, os dados apontam para o estabelecimento, a partir de uma certa ordenação das publicações, uma rede formada por diferentes elos ligados a partir do mesmo objetivo.

PALAVRAS-CHAVE: Estado da Arte. TICs. Ensino. Aprendizagem. SENID. 


\section{Introdução e marco teórico}

O uso das Tecnologias de Informação e Comunicação nos processos de ensino e aprendizagem tem se tornado muito frequente em eventos e congressos que valorizam esta utilização nas salas de aula. Neste desenho, pesquisas têm demonstrado formas e efeitos positivos desta utilização pelos professores no momento pedagógico, derivando na elevação do nível destes congressos. Como objetivo, a grande maioria destes tem o prazer de proporcionar um espaço de reflexão e partilha das investigações sobre o domínio das tecnologias nos ambientes de aprendizagem seja de Educação Básica ou Superior, destinado não somente a todos os que trabalham nas áreas de educação e formação, mas àqueles que, de alguma forma, possuem familiaridade com a temática.

Este movimento é positivo e necessário nas escolas, pois estas instituições, carregadas de estudantes nativos da era digital, estão inseridas em um contexto de conexão e espaços digitais; logo, há a necessidade de mudança eficiente neste contexto, a qual deve fazer com que a escola se aproprie das tecnologias de inclusão digital de forma inovadora, inusitada, revolucionária e criativa, garantindo a aprendizagem do educando por meio destes artefatos tecnológicos.

Desta forma, considera-se que as tecnologias são formas de ampliação de conhecimento e mecanismo de proliferação de saber, isto é, uma ação sobre o saber interligado ao fazer tecnologicamente, favorecendo a formação contínua do professor na teia das tecnologias, pois a partir destes mecanismos desenvolvemse competências e habilidades sobre as diferentes linguagens, informações e comunicações, assim como as distintas representações usadas nas diferentes tecnologias para qualificar os processos de ensino e aprendizagem.

Assim, os congressos possibilitam vida às atividades que os professores desenvolvem ao longo da carreira, pois proporcionam a troca de saberes e experiências aos participantes, elevando a necessidade do trabalho docente estar pautado no uso das tecnologias. No mesmo viés, a identidade do professor se multiplica como autor e ator, favorecendo o desenvolvimento de seus princípios e valores. Além disso, aprecia o modo de situar-se no mundo, de sua história de vida, suas representações e saberes, enfim de sua rede de relações com outros funcionários deste meio, qualificando-se enquanto sujeito da educação.

Deste modo, acredita-se que esses congressos e eventos possuem relevância e importância aos participantes, pois as trocas de informação e experiências que ocorrem nos mesmos elevam, muitas vezes, a qualificação do ensino. Porquanto, parte-se do pressuposto de que quando o docente ou aprendiz da docência participa de eventos deste porte altera à sua realidade com pontos positivos que neles foram destacados, refletindo-se como mecanismos facilitadores a aprendizagem via uso das TICS, assegurando uma formação inicial e/ou continuada.

Neste viés, o artigo em questão busca, por meio de um Estado da Arte ou Estado do Conhecimento, apresentar trabalhos que têm ganhado destaque no Seminário Nacional de Inclusão Digital - SENID , que é um evento anual sobre Inclusão Digital, no norte do estado do Rio Grande do Sul, que vincula tecnologia e educação. Esquadrinha-se, também, detectar e discutir os temas emergentes das 
Brasil - SENID, nas três edições do evento que ocorreram de 2012 a 2014, sobre as indicações do conjunto de estudos que compuseram a temática em questão.

Assim, acredita-se que essa compreensão do estado da arte referente a uma temática, em determinado momento, como explica Soares (1987, p. 3), é necessário no processo de evolução, a fim de

"[...]se ordene periodicamente o conjunto de informações e resultados já obtidos, ordenação que permita indicação das possibilidades de integração de diferentes perspectivas, aparentemente autônomas, a identificação de duplicações ou contradições, e a determinação de lacunas e vieses".

Pesquisas na teia do Estado da Arte são instrumentos que agregam condições e sabedoria na compreensão do conhecimento sobre determinado tema, em determinado período de tempo e, consequentemente, suas sistematizações e análises. Corroborando as escrituras, Sá Barreto e Pahim Pinto (2001), assim como André (2002) e Haddad (2002), enfatizam que o Estado da Arte procura compreender o conhecimento elaborado, acumulado e sistematizado sobre determinado assunto, em um período temporal que, além de resgatar e estudar, condensa a produção acadêmica numa área de conhecimento específica. Particularmente, Haddad (2002, p. 9) reflete que estes estudos

[...] permitem, num recorte temporal definido, sistematizar um determinado campo de conhecimento, reconhecer os principais resultados da investigação, identificar temáticas e abordagens dominantes e emergentes, bem como lacunas e campos inexplorados abertos a pesquisas futuras.

Desta forma, estes tipos de pesquisas revelam trabalhos qualificados por meio de um caráter bibliográfico, procurando revelar de que forma e em que condições estudiosos têm identificado maneiras de produzir conhecimento seja em estudos de pesquisas ou trabalhos aplicados nas indiferentes instituições de ensino. Portanto, o Estado da Arte caracteriza-se como um levantamento bibliográfico, sistemático, analítico e crítico da produção acadêmica sobre uma temática. Legitimando com essa assertiva, Sá Barreto e Pahim Pinto (2001, pp, 5-6) justificam a relevância da organização dessas fontes, quando revelam que:

\footnotetext{
Com os avanços da informática, a seleção de fontes tem podido contar com os bancos de dados existentes, cuja sistematização regular de informações possibilita maior abrangência do levantamento; se, de um lado, eles ampliam o universo contemplado, de outro, armazenam os dados de forma resumida, o que deve ser levado em conta ao se utilizar tais fontes, pois nem sempre os resumos disponibilizam as informações básicas necessárias para análise. 0 ideal, nesses casos, seria o exame dos textos originais, ainda que se admita a dificuldade de acesso a eles. Quando não se dispõe de banco de dados, o próprio processo de elaboração dos estados do conhecimento tem levado à organização desses bancos.
}

Destarte, entende-se que o Estado da Arte possibilita a busca, por meio da pesquisa sobre o que já se construiu ou produziu, por algo novo; o desconhecido. A necessidade de buscar desenvolver atividades de outros cunhos neste mesmo viés, desempenhando sobre as mesmas mais dedicação e atenção, avoluma cada vez mais trabalhos qualificados para um processo de ensino e/ou aprendizagem de forma colaborativa e contextualizada.

Portanto, quando realizado trabalhos desta forma, contribui-se para organizar e definir campos estudados, além de apontar para, como supracitado, 
contribuições a rupturas sociais à luz da inter-relação educação e tecnologia. Assim, estes estados contribuem na constituição do campo teórico de uma temática investigativa, pois proporcionam subsídios de identificação na construção da teoria e da prática pedagógica, apontando para o rumo em que se move as pesquisas e suas lacunas de disseminação, reconhecendo as contribuições do Estado da Arte na constituição de propostas na área focalizada.

Ressalva-se que este trabalho é importante para que o leitor entenda, por meio de uma varredura crítica-reflexiva de cunho virtual-bibliográfica, que as tecnologias fazem parte do processo institucional e que o professor carece de inseri-las como aliadas nos processos de ensino e aprendizagem, a fim de facilitar o seu trabalho e colaborar na aprendizagem cultural, científica e tecnológica do aluno.

Assim, se crê que os educandos possam adquirir condições para enfrentar os problemas e buscar soluções para viver no mundo contemporâneo, sendo capazes de se constituírem atores dos processos, dominarem as linguagens, conduzirem mudanças e resolverem problemas criticamente.

Portanto, o texto, em sua sequência, apresenta o desenho da pesquisa, relatando como foi desenvolvida a coleta de dados e as razões em se optar por estes mecanismos. Concomitante a este, encontra-se os resultados e discussões, aparatos teóricos que apresentam, juntos as matrizes sobre as categorias eleitas, um referencial teórico de cunho explicativo. Em sequência, apresenta-se as conclusões, parte do artigo que destaca, assimetricamente, a riqueza e importância do trabalho. Como término, as referências utilizadas para a confecção deste artigo.

\section{Desenho da Pesquisa}

A coleta de dados para a proliferação e maximização do objetivo frente à pesquisa se deu, como já mencionado, via utilização do Estado da Arte enquanto validação dos trabalhos que mencionam o uso das tecnologias na sala de aula nos três anos de SENID, evento que ocorre anualmente na Universidade de Passo Fundo, o qual conta com a participação de professores, pesquisadores e alunos de distintas cidades do Brasil que visam debater as questões relacionadas às tecnologias e Metodologias de Inclusão Digital.

Com o levantamento bibliográfico frente aos artigos que tangem a conectividade entre educação e tecnologias neste evento, buscou-se interpretar empiricamente os resumos que cada artigo apresentava, pois se acredita que estes apresentam, sucintamente, os principais artefatos dos artigos e resumos expandidos.

Segundo Severino (2002), o resumo consiste na apresentação concisa do conteúdo de um trabalho de cunho científico e tem por finalidade específica de passar ao leitor uma ideia completa do teor do documento analisado, fornecendo, além dos dados bibliográficos do documento, todas as informações necessárias para que o leitor/pesquisador possa fazer uma primeira avaliação do texto analisado e dar-se conta de suas eventuais contribuições, justificando a consulta do texto integral. 
Assim, após análise sobre os resumos disponibilizados na página do evento, houve a necessidade de aprofundar a leitura sobre as publicações, uma vez que a reedição do resumo pelo evento ou a minimização de dados no mesmo deixa algumas passagens fragmentadas, dificultando a leitura e a interpretação dos dados para o Estado da Arte, desmerecendo a elegância dos elementos elucidativos do estudo.

Ainda, destaca-se que, após análise das publicações de forma cuidadosa e cautelosa por meio da Análise Textual Discursiva (MORAES; GALIAZZI, 2006), buscou-se registrá-las, como se apresenta na sequência, sobre matrizes e reflexões epistemológicas dos temas, pois se acredita que o Estado da Arte tem grande validade na medida em que é acompanhado por uma pesquisa de forma qualiquantitativa, apresentando os dados por meio de uma discussão analítica.

Portanto, apresenta-se de forma sistêmica passagens analíticas e fragmentos relevantes puramente importantes para melhor compreensão ao leitor sobre categorias de investigação que emergiram após investigações, interpretações e análises às publicações, dando-se ênfase primordial aos nomes dos autores, tipo de estudo, tema da pesquisa e aspectos sobre a ostentação nos processos de ensino e aprendizagem.

\section{Resultados e Discussões}

Considerando que a análise no viés do Estado da Arte, em determinado espaço temporal, deve considerar o processo de construção de conhecimento sobre determinado tema, "[...] identificando-se as contribuições, reconhecer os principais resultados da investigação, identificar temáticas e abordagens dominantes e emergentes, bem como lacunas e campos inexplorados abertos à pesquisa futura" (Haddad, 2002, p. 9), tem-se em mente que a construção deste tipo de estudo proporciona a viabilidade que o evento fornece sobre as publicações vinculadas à tecnologia na área de educação.

O desenho da pesquisa deu-se a partir de visitações à página do evento em questão, considerando que os pesquisadores investigaram, interpretaram e analisaram todos os artigos disponíveis na página durante o desenvolvimento do SENID.

Para a interpretação dos dados presentes na leitura dos resumos e artigos optou-se, para emersão de categorias, analisar as escrituras por meio da Análise Textual Discursiva (ATD), isto é, constroem-se metatextos a partir da ligação realizada na interpretação. Em outras palavras, realizou-se uma análise qualitativa por meio da ATD, pois se tem que é uma abordagem de análise de dados que transita entre duas formas consagradas de análise na pesquisa qualitativa: análise de conteúdo e a análise de discurso.

Estas se apoiam de um lado na interpretação do significado atribuído pelo autor e de outro nas condições de produção de um determinado texto (Moraes e Galiazzi, 2006, p. 118). Assim, para interpretar os dados e realizar a análise foi preciso separar as escrituras por significado, caracterizando-se pela unitarização.

Oriundas da conexão empírica, as interpretações sobre as escrituras geraram novas unidades que foram analisadas e interpretadas, considerando que são originárias da conexão teórica. Apropriando-se de outras vozes e condizendo-se as 
inter-relações que se deram na análise dos artigos, emergiram-se, à luz de reflexões sistêmicas sobre o Estado da Arte, quatro categorias que mais se destacaram na leitura dos artigos. Observe a tabela abaixo. (Ver Tabela I).

Neste viés, optou-se em apresentar, para não minimizar o número de artigos completos e resumos disponibilizados/apresentados no evento, dentro das categorias emergentes da análise analítica, artigos que, de alguma forma, foram relevantes no processo categorial seja pelo pretexto ou contexto apresentado.

A tabela a seguir (Tabela I), apresenta em categoria, a análise das publicações que comportaram os três anos de evento. Analisando-a, pode se perceber que um total de 20 publicações foram selecionadas no primeiro ano de evento, seguido de 16 no segundo e 15 no terceiro; logo, um total de 51 publicações foram analisadas para o Estado da Arte que compõe este artigo.

Tabela I: Total de publicações (anual) analisadas divididas em categorias.

Categorias

Educação a distância

Educação especial

Formação de professores

Recursos tecnológicos

Total
2011

0

4

2

14

20
2012

1

1

5

9

16
2013 1

2

5

7

15 
Da mesma forma, confeccionou-se, a partir dos dados da Tabela I, um gráfico que fornece um panorama geral da distribuição dos trabalhos nas categorias de análise em relação às publicações avaliadas. Esse gráfico evidencia (Ver Gráfico I), dentro das categorias emergentes na interpretação, as áreas que receberam maior quantidade de trabalhos para validação e publicação no evento, no período de 2012 a 2014.

Gráfico 1 - Publicações analisadas em percentual de categorias

\section{PUBLICAÇÕES ANALISADAS EM PERCENTUAL DE CATEGORIAS}

• Educação a distância

Educação Especial Formação de professores

Recursos tecnológicos

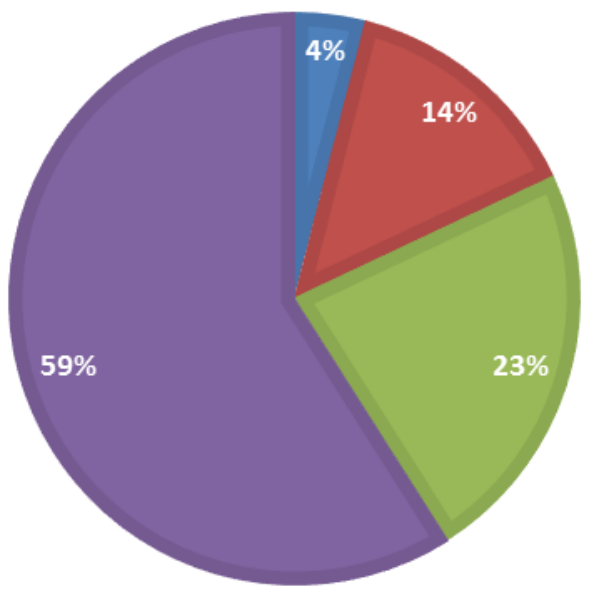

Ao tocante, destaca-se que serão apresentadas, teoricamente, na sequência as categorias que emergiram a partir da Análise Textual Discursiva, dando-se ênfase em alguns artigos que melhor representam as ideias, concepções e perspectivas dos trabalhos analisados em cada categoria, a fim de dar suporte e vida a estas. Ressalta-se, também, que no início de cada categoria é apresentando um parágrafo que reflete e informa a necessidade, importância e relevância de cada categoria ser estudada e qualificada no berço das escolas públicas.

\section{Categoria I: Educação a Distância - EaD}

Uma das categorias eleitas, após a análise e interpretação sobre as publicações, foi Educação à Distância. Uma reflexão por meio do Estado da Arte desta categoria é de suma importância nos dias de hoje, pois se tem que esta modalidade de ensino está evoluindo de forma exacerbada; crescendo e tomando espaço nas diferentes instituições de ensino, pois se deriva como esfera capaz de duplicar a capacidade do sistema de educação superior, mantendo a qualidade do ensino e da formação profissional, visto que se utiliza o meio tecnológico como ferramenta de apoio para o aprendizado.

Esta abrangência da EaD permite uma forma diferente de ensino, pois a interatividade entre os participantes ocorre de forma síncrona via utilização das TICS, isto é, as ferramentas de informação e comunicação são adotadas com o objetivo de facilitar os processos de ensino e aprendizagem, estimulando e instigando a colaboração e interação entre os participantes de forma autônoma e 
crítica. Corroborando as escrituras, Moraes (2002, p. 203) reflete que, em qualquer situação de aprendizagem, a interação entre os participantes é de extrema importância, tornando-se possível a troca de experiências, o estabelecimento de parcerias e a cooperação.

Dentro desta categoria, totalizando 4\%, enfatiza-se o artigo de Parise, Parise, Maran e Battisti (2014), pois este se baseou em uma análise de trabalhos nacionais relacionados ao u-learning, isto é, uma área que trata da integração de metodologias de ensino com tecnologias provenientes da computação ubíqua, com o intuito de refletir sobre o estado atual da Educação a Distância no Brasil e a integração desta tecnologia em sistemas computacionais para a área de educação. Conforme os autores, no contexto educacional, novas tecnologias estão mudando e revolucionando o conceito de educação e a forma como a entendemos hoje. A tecnologia possibilitou o ensino à distância e agora encurta os caminhos e aproxima as modalidades à distância e presencial através da Computação Ubíqua (ubicomp) (p.1)

Desta forma, os autores enfatizam que a aprendizagem ubíqua pode ser entendida como a utilização de dispositivos e tecnologias móveis, sensibilidade ao contexto e tecnologias de comunicação sem fio, objetivando auxiliar a construção de conhecimento e levando em consideração as características peculiares dos estudantes, auxiliando no processo educacional. Ainda, concluem que a criação de objetos de aprendizagem, que serão adaptados para os estudantes, exige competências e habilidades do professor, pois o mesmo deve estar adaptado pedagogicamente a esses objetos, os quais devem vir a somar, desta forma, no aprendizado dos alunos.

\section{Categoria II: Formação de Professores}

Não é possível pensar a educação nos tempos atuais sem discutir sobre mudanças estruturais na forma de construir o conhecimento pela mediação tecnológica no trabalho docente, uma vez que a exigência de novos padrões de produtividade e competitividade, em função dos avanços tecnológicos, vem afetando não apenas os processos de ensino e aprendizagem, mas também a forma em que o professor planeja e executa sua aula, auxiliando na construção do conhecimento e na contextualização com a vida.

Sendo assim, as tecnologias devem ser pensadas e utilizadas de forma a contribuir com o trabalho dos professores, sendo naturalmente incorporadas no currículo de formação à docência, visando preparar profissionais autônomos, reflexivos e capazes de adaptar suas estratégias didáticas. Neste desenho, acredita-se que a utilização das tecnologias para a formação do professor, efetivamente como ferramentas dos processos de ensino e aprendizagem, estará fortemente influenciando a emersão de competências e habilidades para este viés, uma vez que, segundo Valente (1993, p. 23), a formação do professor deve prover condições para que ele construa conhecimento sobre as técnicas computacionais.

Dentre os artigos analisados nesta categoria, correspondentes a $23 \%$, destacase o trabalho de Pessoa, Costa e Ragone (2014), pois trata de uma revisão a respeito das Tecnologias Digitais de Informação e Comunicação (TDIC) e sua 
tecnologias na formação docente, com o objetivo de compreender melhor o tema e suas implicações na formação docentes e nos processos de ensino e aprendizagem.

Na sequência, os autores realizaram uma atividade na disciplina Informática e Educação (ministrada por um dos autores do trabalho), com alunas do 1o período de Pedagogia da Fundação Helena Antipoff, situada em Ibirité, Minas Gerais. Esta atividade envolveu leitura, discussões e um questionário o qual almejava averiguar como as alunas compreendiam o emprego da TDIC na sala de aula e qual o papel do professor dentro deste contexto.

Desta forma, pode-se averiguar que os autores acreditam que as TDCI são de grande relevância para os processos de ensino e aprendizagem na sociedade tecnológica atual, contudo, apontam que os professores precisam estar preparados para esta ação, uma vez que observaram, neste curso de formação inicial, que os futuros professores se mostraram inseguros e despreparados para lidar com esses recursos tecnológicos.

Observou-se que todos os trabalhos analisados nesta categoria de análise trazem uma reflexão sobre a preocupação da formação docente frente ao uso das tecnologias à luz da qualificação dos processos de ensino e aprendizagem, tanto no que se refere a formação inicial ou contínua, bem como na utilização do recurso EAD nestes processos. Desta forma, há de se reconhecer que, mesmo que lentamente, existe a inserção de novos artefatos tecnológicos na formação docente, buscando a valorização dos processos de ensino e aprendizagem.

\section{Categoria III: Educação Especial}

A formação inicial dos professores precisa focar na utilização das tecnologias, considerando uma cultura extremamente tecnológica como meio de produção do conhecimento, minimizando a resistência e a evasão por estes materiais no ensino. Neste aporte, entende-se que há a necessidade de que os professores sejam, também, formados para a diversidade; que o professor desenvolva, ainda na graduação, competências e habilidades para trabalhar com todo o público em geral, principalmente com aqueles portadores de necessidade especial, promovendo suas aprendizagens e suas práticas dentro de suas limitações e particularizações.

Desta forma, oportuniza-se, por meio das tecnologias, que o educando com necessidades educacionais especiais aprenda, interaja, crie e supere suas próprias barreiras, abstraindo e aplicando o que aprende. Assim, tem-se em mente que esta criança assumirá posição de autonomia e criticidade, buscando soluções para os problemas diários e agudizando a distância entre a criança e o mundo sóciocientífico.

Desta forma, destaca-se, dentre as publicações que refletem a temática durante os três anos do evento SENID, o artigo de Soares, Lira, Santos, Oliveira e Costa (2013), pois dentre os vários artigos, este é o que melhor representa as ideias dos trabalhos apresentados nessa categoria. Este artigo relata as atividades desempenhadas na escola Especial Irmã Benigna, localizada em Patos-PB, acerca das expectativas habituais de alunos com limitações visuais em utilizar a tecnologia da informação como ferramenta auxiliadora na superação de suas dificuldades. 
$\mathrm{Na}$ visão dos autores, as TICs são vistas como ferramentas de apoio para professores e alunos. Assim, aplicá-las no ensino especial significa dar uma reestruturação, não maquiagem, nos processos de ensino e aprendizagem, aprimorando o desenvolvimento do raciocínio lógico dos portadores de necessidades especiais, revendo novas formas de transmissão e de assimilação do conhecimento, inserindo-os nesse mundo globalizado. Destarte, trazem como reflexão final que a utilização das tecnologias assistivas pelos estudantes corrobora na autonomia e independência, bem como na construção do seu conhecimento e, por consequência, inclusão no meio social, cultual e tecnológico.

O trabalho de Spagnoto, Tedesco e Oliveira (2014), apresenta um breve relato sobre tecnologias assistivas e a importância das mesmas para a construção da autonomia de pessoas com necessidades especiais. $O$ estudo em questão teve o intuito de analisar a utilização de recursos e equipamentos de Tecnologia Assistiva no desempenho de atividades educacionais, especialmente no que se menciona à disponibilidade desses para o aluno, no caso crianças com deficiência intelectual.

Os pesquisadores destacam, ainda, que para que ocorra a Inclusão dessas no ensino regular é necessário que a instituição esteja em adaptação contínua, uma vez que para isso é preciso que a escola inclusiva atenda de fato a diversidade e que gere oportunidades, experiências, aprendizagens e estratégias pedagógicas e de ensino, para que todos os alunos possam ter êxito no seu processo de aprendizagem, disponibilizando os recursos de Tecnologia Assistiva, a fim de promover uma educação para todos. Salientam também que incluir não é somente inserir o aluno no contexto escolar, mas permitir que ele tenha acesso fácil a tudo aquilo que está disponível na escola, como os livros da biblioteca, por exemplo.

Os demais trabalhos analisados nesta categoria tratam de outras deficiências, como visual, auditiva e intelectual. Entretanto, todos os estudos se direcionam a ampliação dos modos de inclusão destes alunos no sistema de ensino, no sentido de que estes alunos possam se apropriar e usufruir de uma tecnologia que atenda às suas necessidades e expectativas.

\section{Categoria IV: Recursos Tecnológicos como Ferramentas de Ensino e aprendizagem}

Tem-se vivido uma era em que as tecnologias podem ser usadas como aliadas nos processos de ensino e aprendizagem, pois as mesmas valorizam estes processos na forma em que são trabalhadas, isto é, atualização do conteúdo, auxílio nos processos de assimilação e acomodação dos saberes, interatividade, permanência e independência na aprendizagem são mecanismos internalizados/superados pelos alunos ao usar as TICs.

Nesta vertente, acredita-se que além de auxiliar o professor no momento pedagógico, as tecnologias trazem ao ambiente escolar uma forma diferenciada à aprendizagem seja por meio da criatividade, do entretenimento ou da curiosidade. $\mathrm{O}$ interessante em usar tecnologias como aliadas aos processos de ensino e aprendizagem é que as mesmas motivam o educando a buscar conhecimento, tornando-se autor da própria formação (autor, ano). Assim, o uso de TICs na que o educador que utiliza tecnologias em suas aulas pode obter resultados 
significativos, os quais contribuem para um ensino qualificado bem como a melhoria de sua prática pedagógica (Borba e Penteado, 2005).

Nesta esfera, por mais amplo que tenha sido as publicações e análises, comportando 59\%, salienta-se os artigos de Kusiak, Prestes, Schmidt e Franzin (2012) e Kusiak, Prestes e Retzlaff (2013), pois estes apresentam a descrição de aplicação de softwares livres (Geogebra e Wingeon, respectivamente), para entender e refletir sobre os conteúdos Geometria Plana e Espacial, por acadêmicos integrantes do Pibid. Em ambos os artigos, os autores descreveram as percepções do grupo enquanto acadêmicos, suas reflexões e indicações para trabalhos futuros após a realização dessa experiência. Destaca-se que vários projetos envolvendo TICs vêm sendo desenvolvidos no âmbito do Pibid, por exemplo, os descritos nestes artigos e em outros referenciais na área de física Pastorio et al. (2011) e química Costa e Oliveira (2012)

Os autores comentam que as aplicações das oficinas obtiveram grande aceitação por parte dos alunos, pois se mostravam interessados em participar, relatando terem gostado da experiência de trabalhar com ambos os softwares, visto como os aplicativos proporcionando aos alunos uma melhor visualização das figuras, possibilitando aprender com o erro e fazer comparações de forma dinâmica aos conceitos geométricos.

Sobre o uso das redes sociais como recursos tecnológicos para a maximização dos processos de ensino-aprendizagem, para as mais diversas áreas do conhecimento, destaca-se o artigo de Gengnagel (2012), o qual almejou demonstrar como a utilização de blogs na disciplina de Geografia é rica e necessária. O professor, que é autor do trabalho, relata que os blogs começaram a receber cada vez mais conteúdos, fazendo com que os alunos interagissem com outros colegas, melhorando a relação professor-aluno, os materiais e multiplicando o interesse pelos conteúdos da disciplina.

Gengangel (2013), também apresenta a rede social facebook como proposta para potencializar o processo de motivação e interesse dos educandos para o ensino, a partir de uma proposta didática intermediada pelo professor. $\mathrm{O}$ autor comenta que os recursos tecnológicos, que já são utilizados e dominados pelos alunos, podem ser um dos meios para se alcançar a motivação explicitada e o aprendizado pretendido.

Neste desenho, outro artigo analisado foi de Brezolin e Grando (2013) o qual apresenta as contribuições do uso de mapas conceituais, por meio da ferramenta de autoria CMap-Tools, como estratégias de ensino e aprendizagem na era digital. Segundo os autores, o uso da ferramenta na construção de mapas conceituais potencializou a colaboração na produção e diversificação dos mesmos, permitindo aos alunos a criação de mapas ricos em representações do conhecimento científico contextualizado ao senso comum. As imagens, vídeos e hiperlinks puderam ser associados aos conceitos representados nos mapas, agregando as contribuições de outras pessoas a sua própria produção, proporcionando ao aluno uma reflexão sobre seu próprio processo de aprendizagem na relação com o outro.

Quanto aos demais trabalhos analisados nesta categoria, ressalva-se que estes trazem a utilização de jogos educativos (atividades lúdicas), mídias, softwares e robótica como possibilidades didático-pedagógicas, as quais visam melhorar os processos educacionais. Contudo, convém destacar que existem limitações no uso dos equipamentos, bem como da apropriação das tecnologias, jogos e software 
pelas escolas, mas os professores e alunos devem buscar a incorporação destes aos processos de ensino e aprendizagem.

\section{Conclusão}

Este estudo constatou, na solicitude do Estado da Arte, algumas categorias que, na imperatividade das análises, surgiram como meio de facilitar a investigação das publicações frente ao uso das Tecnologias de Informação e Comunicação para a qualificação dos processos de ensino e aprendizagem no evento SENID. A análise se deu via leitura formal dos artigos completos e resumos expandidos, pois uma leitura superficial dos resumos que pairavam sobre as publicações foi incompatível aos objetivos do artigo, encontrando-se algumas limitações que dificultaram e, em alguns casos, prejudicaram a categorização e a análise do seu conteúdo, por exemplo, a falta de palavras-chave, desenho da pesquisa.

A análise sobre as publicações trouxe quatro categorias fundamentais que se ramificaram, com o passar do tempo, no evento. Em uma ordem crescente cronológica sobre as publicações de cada categoria, averiguou-se que se sobressaem: Educação a Distância, Educação Especial, Formação Docente, e Recursos/ferramentas tecnológicos. Assim, entende-se que ainda se busca investigar e estudar as TICs na formação docente e na qualificação do ensino, almejando melhorias na educação.

Analisou-se um total de 51 trabalhos, sendo que deste total classificaram-se $2 \%$ como categoria Educação a Distância, 14\% Educação Especial, 23\% Formação de Professores e 59\% Recursos/ferramentas tecnológicos. Na categoria Educação a Distância, foram encontrados dois trabalhos empíricos, os quais foram analisados e discutidos na íntegra. O pequeno valor de trabalhos presentes nesta categoria justifica-se no fato de que os outros trabalhos, apesar de tratarem de EAD, encaixavam-se melhor nas outras categorias.

Na categoria Educação Especial, foram encontrados sete trabalhos, sendo que dois foram discutidos de forma incorruptível. Após a análise, verificou-se que alguns trabalhos tratavam de outras deficiências, como visual, auditiva e intelectual, enquanto que outros traziam estudos direcionados a ampliação dos modos de inclusão de alunos, para que estes possam se apropriar e usufruir de uma tecnologia que atenda às suas necessidades particulares.

Na categoria Formação de Professores, foram analisados 12 trabalhos, mas discutidos e apresentados na íntegra apenas dois, uma vez que trouxeram uma reflexão sobre a preocupação da formação docente, tanto no que se refere a formação inicial ou contínua, quanto na utilização do recurso EAD nos processos de formação. Na última categoria de análise, Recursos/Ferramentas Tecnológicos, observou-se o relato de utilização de redes sociais, jogos educativos (atividades lúdicas), mídias educativas, softwares e robótica como possibilidades didáticopedagógicas visando sempre a qualificação dos processos de ensino e aprendizagem.

Destarte, diante dos fatos apresentados nas categorias, mais especificamente por baixo de todas as questões, está o ponto mais desafiador e, quiçá, mais importante. Em meio a todas essas concepções de inserção de tecnologias, tanto no âmbito formativo quanto social, sugestões de intervenção e aprimoramentos, tem-se que reconhecer que o apoio do setor público para o uso das diferentes 
tecnologias pode apenas ir até este ponto. Em outras palavras, há a necessidade do âmbito educacional, em especial o professor, perceber que as mudanças das metodologias e da qualificação dos processos de ensino e aprendizagem podem prover da inserção das TICs. Neste sentido, os indivíduos devem assumir as responsabilidades de seu envolvimento com as TICs e agir de modo reflexivo rumo ao uso destas.

Este desenho do Estado da Arte, como suporte organizacional de aplicações das TICs, tem o intuito de contar a história sobre o evento, pois a abrangência e diversidade da produção sobre um mesmo norte originaram para a discussão um conjunto de vertentes que enriqueceram a concepção sobre a utilização das TICS na educação, mostrando sua complexidade e relevância para os estudos da área. De todo modo, pode-se estabelecer, a partir de uma certa ordenação de publicações, uma rede formada por diferentes elos ligados em consonância à um mesmo objetivo seja pela opção teórica, pelo eixo norteador do trabalho ou pelo procedimento metodológico adotado pelo pesquisador.

Ainda, destaca-se que os Estados da Arte demandam tempo para a realização e investigação das leituras, exigindo abrangência e delimitação explícita sobre a temática, uma vez que os dados obtidos neste viés possibilitam uma abertura muito grande para sua análise. Por conseguinte, acredita-se que a diligência empreendida nesta pesquisa, referente à temática supracitada, compor-se-á em subsídios para os estudiosos da área, sobretudo, na compreensão do percurso da aplicabilidade das TICs no momento pedagógico à luz da aprendizagem. 


\title{
Technology and Education: State of the Art in landscaping SENID
}

\begin{abstract}
This article brings results of a survey critical and reflective nature of virtual-bibliographical, held in the bias of the three years of the event National Digital Inclusion Seminar (SENID) on publications regarding the use of technology and the qualification processes teaching and learning, exacerbated as a support for teacher training, public policies, curriculum more flexible. Data analysis was performed forward State of the Art of the nature qualiquantitative via use of full papers and extended abstracts available on the event page. It was found, by means of the publications the design of the State of the Art, the emergence of four categories in the bias those ending in the thematic last three yearS SENID, publications regarding the use of technology in education. Regardless, of data point to the establishment, from a certain ordering of publications, a network formed by different links connected from the same goal.
\end{abstract}

KEYWORDS: State of the Art. TICs. Teaching. Learning. SENID. 


\section{NOTAS}

10 Seminário Nacional de Inclusão Digital - SENID - é um evento promovido pelo Grupo de Pesquisa em Inclusão Digital - GEPID, vinculado ao Curso de Ciência da Computação e ao Programa de Pós-graduação em Educação da Universidade de Passo Fundo - UPF. A primeira edição do SENID foi promovida entre os dias $16 \mathrm{e}$ 18 de abril de 2012, a segunda entre os dias 8 e 10 de abril de 2013. A terceira edição, por sua vez, entre os dias 28 e 30 de abril de 2014. Em todas as edições o evento convida professores, funcionários, estudantes e comunidade em geral a apresentar suas atividades de investigação.

2 Objetos de Aprendizagem são pequenos componentes instrucionais que podem ser reutilizados inúmeras vezes em diferentes contextos de aprendizagem (Wiley, 2000).

3 O PIBID é uma iniciativa da Coordenação de Aperfeiçoamento de Pesquisa de Nível Superior (CAPES), que incentiva o aperfeiçoamento e a valorização da formação de professores para a educação básica, através da concessão de bolsas a alunos de licenciaturas que participam de projetos de instituições de ensino superior em parceria com escolas públicas.

4 O CMap-Tools é um software livre para autoria de mapas conceituais, desenvolvido pelo Institute for human Machine Cognition da Universidade de West Florida, sob a supervisão do Dr. Alberto J. Cañas, para construir, navegar, compartilhar e criticar modelos de conhecimento representados por mapas conceituais.

\section{REFERÊNCIAS}

ANDRÉ, M. E. D. de. Formação de professores no Brasil (1990-1998). Brasília: MEC/Inep/ Comped, 2002.

AMSTRONG, A.; CASEMENT, C. A criança e a máquina: como os computadores colocam a educação de nossos filhos em risco. Trad. De Ronaldo Cataldo Costa. Porto Alegre: Artmed, 2001.

BORBA, M. C. e PENTEADO, M. G. Informática e educação matemática. 3. ed. Belo Horizonte: Autêntica, 2005.

BREZOLIN, J. M. L.; GRANDO, N, I. Mapas conceituais: uma proposta da avaliação do processo de ensino e aprendizagem na era digital. SEMINÁRIO NACIONAL DE INCLUSÃO DIGITAL, Passo Fundo, 2013.

COSTA, C. B.; OLIVEIRA, G. S. O PIBID e o uso das tecnologias da informação e comunicação (TICS) no ensino de química. In: CONGRESSO BRASILEIRO DE

QUÍMICA, Recife, 2012 
GARRIDO, E. A técnica close e a compreensão da leitura: Investigação em textos de estudos sociais para a 6ạ série. Dissertação de mestrado, USP. São Paulo, 1979.

GENGNAGEL, C. L.; Redes sociais e educação: A utilização da ferramenta blogs nas aulas de geografia. SEMINÁRIO NACIONAL DE INCLUSÃO DIGITAL, Passo Fundo, 2012.

GENGNAGEL, C. L.; Educação e redes sociais: uma experiência no ensino médio. SEMINÁRIO NACIONAL DE INCLUSÃO DIGITAL, Passo Fundo, 2013.

HADDAD, S. Juventude e escolarização: uma análise da produção de conhecimentos. Brasília: MEC/ Inep/ Comped, 2002.

KUSIAK, R. S.; PRESTES, R. F.; SCHMIDT, D.; FRANZIN, R. F. F. A Utilização do Software Geogebra no Ensino da Geometria Plana: Uma Experiência PIBID. SEMINÁRIO NACIONAL DE INCLUSÃO DIGITAL, Passo Fundo, 2012.

KUSIAK, R. S.; PRESTES, R. F.; RETZLAFF, E. Utilização do Software Livre Wingeom: Uma Proposta PIBID para o Ensino da Geometria Espacial. SEMINÁRIO NACIONAL DE INCLUSÃO DIGITAL, Passo Fundo, 2013.

MORAES, M. C. Educação a distância: fundamentos e práticas. Campinas, SP: Unicamp/Nied, 2002. Disponível em: http://www.escolanet.com.br/sala leitura/ogead.html. Acessado em 27, out. 2014.

MORAES, R.; GALIAZZI, M. do C. Análise Textual Discursiva: processo reconstrutivo de múltiplas faces. Ciência \& Educação, v. 12, n. 1, p. 117-128, 2006.

PARISE, D.; PARISE, M.; MARAN, V.; BATTISTI, G. U-Learing - O futuro EAD? SEMINÁRIO NACIONAL DE INCLUSÃO DIGITAL, Passo Fundo, 2014.

PASTORIO, D. P.; RUBERT, C. C.; ROSA, F.; SAUERWEIN, I. P. S. Atividades de iniciação à docência mediadas por hipermídias educacionais no ensino de física. In: SIMPÓSIO NACIONAL DE ENSINO DE FÍSICA, 19, 2011, Manaus. Atas. São Paulo: Sociedade Brasileira de Física, 2011. p. 1-8

PESSOA, G. P.; COSTA, F. J.; RAGONE, R. A. Investigação preliminar com estudantes de pedagogia: inserção das tecnologias digitais de informação e comunicação (TDCI) na formação docente. SEMINÁRIO NACIONAL DE INCLUSÃO DIGITAL, Passo Fundo, 2014. 
SÁ BARRETO, E. S. de.; PAHIM PINTO, R. Avaliação da educação básica (1990 1998). Brasília: MEC/ Inep/Comped, 2001.

SEVERINO, A. J. Metodologia do trabalho científico. 22. ed. rev. ampl. São Paulo: Cortez, 2002.

SOARES, M. B. As pesquisas nas áreas específicas influenciando o curso de formação de professores. Cadernos ANPED, n. 5, set. 1987.

SOARES, A. L.; LIRA, E. P.; SANTOS, J. S.; OLIVEIRA, P. R. F.; COSTA, R. A. Investigando a tecnologia assistida para deficientes visuais através de uma experiência de estágio supervisionado. SEMINÁRIO NACIONAL DE INCLUSÃO DIGITAL, Passo Fundo, 2013.

SPAGNOLO, C.; TEDESCO, S.; OLIVEIRA, V. M. T. de.; Currículo adaptado e Tecnologias Assistivas: apoio ao aprendizado de crianças com necessidades especiais. SEMINÁRIO NACIONAL DE INCLUSÃo DIGITAL, Passo Fundo, 2014.

VALENTE, J. A. Um laptop para cada aluno: promessas e resultados educacionais efetivos, 2011. In Alemeida, M. E. B.; Prado, M. E. B. B. (Org.) O computador portátil na escola: mudanças e desafios nos processos de ensino $\mathrm{e}$ aprendizagem. São Paulo: Avercamp.

WILEY, D. A. (2000) Connecting learning objects to instructional design theory: A definition, a metaphor, and a taxonomy. In: (Ed.). The Instructional Use of Learning Objects: Online Version, 2000. Disponível em: http://citeseerx.ist.psu.edu/viewdoc/download?doi=10.1.1.532.4034\&rep=rep1 \&type=pdf. Acessado em 15, mar. 2016. 
Recebido: 14 jan. 2015.

Aprovado: 20 nov. 2016.

DOI: 10.3895/rbect.v9n3.2744

Como citar: BEDIN, E.; LOCATELLI, A.; BEDIN, R. J. Tecnologia e Educação: Estado da Arte no

paisagismo do SENID. Revista Brasileira de Ensino de Ciência e Tecnologia, v. 9, n. 3, 2017. Disponível

em: <https://periodicos.utfpr.edu.br/rbect/article/view/2744>. Acesso em: xxx.

Correspondência:

Direito autoral: Este artigo está licenciado sob os termos da Licença Creative Commons-Atribuição 4.0

Internacional.

\section{(c) (1)}

